\section{Presenting behavioural genetics: spin, ideology, and our narrative interests}

\author{
N C Manson
}

\section{Abstract}

A short review is given of the Nuffield Council's report on behavioural genetics. This review is used as an entry point to a discussion of the factors that influence the presentation of behavioural genetics in the media and in the popular scientific press. It is argued that our interest in formulating narrative explanations of our individual lives puts pressure on publishers and editors to present behavioural genetics in a selective, misleading way. Some other influences on presentation are discussed and it is suggested that the Nuffield report is particularly useful in so far as it lacks these distorting influences.

$\mathrm{T}$ he Nuffield Council on Bioethics has recently published a report on behavioural genetics: Genetics and Human Behaviour: The Ethical Context. ${ }^{1}$ The report aims to stimulate and inform debate about behavioural genetics by offering a survey and evaluation of (a) current empirical research in behavioural genetics, and (b) the attendant ethical, legal, and social implications of such research. The specific focus is upon quantifiable behavioural traits, in particular, upon continuously distributed behavioural traits that fall within the "normal" range-that is, two standard deviations, or approximately $95 \%$ of the population. The first part of the report outlines the historical origins of behavioural genetics and then introduces the various branches of contemporary behavioural genetics: quantitative genetics (including family, twin, and adoption studies); molecular genetics (especially molecular genetics in neuroscience), and animal studies.

Quantitative genetic research studies heritability. Heritability is an estimate of the amount of variance within a population (within a particular type of environment) that is explicable in terms of genetic, as opposed to environmental, factors. Changing the environment can change heritability. By making the environment more uniform, any variation within a population is more likely to be explicable in terms of genetic factors. We can thus increase (or decrease) heritability of behavioural traits. Heritability of behavioural traits does not imply immutability; heritability does not imply "genetic determinism"; heritability is a concept that applies to populations, not to individuals, so findings about heritability cannot be used to support claims about an individual's genetic "inheritance". The fact that a behavioural trait, such as intelligence, has a heritability of somewhere between 0.3 and 0.7 does not allow us to say anything by way of explaining a particular person's intelligence. None of us can claim (at least on the basis of current behavioural genetics) that our particular level of intelligence has a 50/50 genetic/environmental basis: findings about heritability just do not apply to individuals and they do not, by themselves, tell us anything about which gene or set of genes might be causally relevant to the occurrence of a particular behavioural trait.

Molecular genetics, by way of contrast, seeks to identify the function of particular genes by examining the DNA of individual subjects. In association studies-for example, a comparison is drawn between (a) the frequency of a particular genetic variant (identified via tests upon DNA) within a group of subjects who exhibit some trait, and (b) the frequency of the genetic variant in a control group whose members do not exhibit the trait in question. Matters are made more complex, however, because many genes (and many environmental influences) are involved in the causation of any behavioural trait.

Animal studies have the advantage that researchers are not merely restricted to observing the extant distribution of behavioural traits. Some animal studies use the traditional method of selective breeding to change the phenotypic traits of, or the distribution of phenotypic traits within, selected animal populations, but such studies do not tell us anything about the underlying molecular mechanisms involved in the formation of particular traits. Other animal studies are more informative about the relation between molecular genetic material and phenotypic traits. Researchers can bring about changes in the genotype of an animal and observe the effects of such changes (relative to fixed environments). Researchers can create genetically modified animals by, for example, deleting ("knocking out") a particular gene, or by transferring genes between species (creating "transgenic" animals). In one study, for example, mice were genetically altered so that they overexpressed a gene thought to be involved in learning. ${ }^{2}$ The modified mice appeared to have an improved capacity for learning and memory.

Having introduced these strands of contemporary behavioural genetics in the first part of the report, the second part involves a review of the contemporary findings with regard to variation in: intelligence; personality; antisocial behaviour, and sexual orientation. This review of research provides the basis for the third part of the report, which explores the ethical, legal, and social issues that arise, or that may arise, from both current and future findings in behavioural genetics.

The overall tone of the report, especially in the second and third parts, is one of caution. The authors stress the complex nature of gene/gene and gene/ environment interactions and they draw attention to a number of methodological problems that bedevil behavioural genetics, such as: how can quantitative geneticists properly identify the "same" environments in twin and family studies? What is it for two environments to be the same (given that the "same" environment might have very different effects on different individuals)? Molecular genetics, as applied to human behavioural traits, faces its own problems. Most behavioural traits involve the activity of a great number of genes and also require the right kind of complex developmental environment. How can we legitimately make inferences about human behaviour on the basis of animal studies? Some nonhuman mammals may be genetically similar to humans in some respects, but they are also genetically different and, more importantly, they differ hugely from human beings with regard to their social, linguistic, and cultural environment-that is, they more or less lack such environmental influences). Although molecular geneticists do have rich statistical analytical resources at their disposal, most of the associations 
between genetic variants and behavioural traits identified by researchers have, so far, been notoriously hard to replicate. Furthermore, the discovery of such associations does not, by itself, establish genetic causation.

At this point it is important to distinguish two broad types of ethical issue that arise with regard to genetic research. The first type of issue arises with regard to the acquisition of genetic knowledge (research ethics, for example, is one species of this broad type). The second type of issue arises with regard to the uses of genetic knowledge once it has been acquired. The ethical issues discussed in the Nuffield report are largely of the second type. The methodological problems that face behavioural genetics put serious constraints upon the acquisition, and thus upon the practical use, of behavioural genetic knowledge. Genetic testing of individuals, for example, requires some way of applying genetic knowledge to an individual subject. Quantitative genetics is inappropriate in so far as measures of heritability apply to population, not to individuals. Animal studies may be of little help given the differences between animal and human behaviour. We cannot selectively breed people to test hypotheses about heritability of behavioural traits. The best bet seems to come from molecular genetics used in consort with quantitative behavioural genetics. The authors of the report offer, once again, a cautious conclusion:

\begin{abstract}
In light of the lack of findings that have been replicated in research in behavioural genetics using molecular genetics techniques in this field, there are currently no practical applications of the research. There are no genetic tests for behavioural traits, nor are there pharmacological interventions that have been developed based on information about genetic influences on behavioural traits in the normal range (Nuffield Council on Bioethics,' 11.7).
\end{abstract}

Even if current findings in behavioural genetics are not robust enough to underwrite, say, prenatal genetic testing for behavioural traits in the normal range, it is important to try to anticipate findings in this field, and to address the ethical implications of developments in behavioural genetics in order to avoid being "caught short" by the developments after they have occurred. The third part of the report is concerned with "Ethical, Legal and Social Issues" (ELSI) that are likely to be raised with regard to prenatal and individual diagnostic genetic testing, genetic interventions, and the use of genetic testing in employment, education, and insurance, if behavioural genetics turns out to provide robust, individually applicable genetic knowledge.

Given that it is not clear how behavioural genetics is going to develop, no precise formulation of policy or regulation is offered. Instead, we are given a set of measured and sensible proposals as to how we should balance, on the one hand, the benefits that might be gained from developments in behavioural genetics and, on the other hand, the various personal and social costs that may result from people's use of genetic knowledge in genetic testing, genetic interventions, and so on.

\section{INTERESTS THAT SHAPE THE PRESENTATION OF BEHAVIOURAL GENETICS}

Reading the Nuffield report gives a particular impression of behavioural genetics, one that seems to be quite different from the behavioural genetics that we encounter in the press and in certain popular scientific presentations. The authors of the report are well aware of this fact and draw attention to the disparity between behavioural genetics as it really is, and behavioural genetics as it is presented in the media.

[R]eports of such things as "gay genes" or "smart mice" convey a highly inaccurate impression of the state of the research. The lack of reporting of negative or contradictory findings exacerbates this problem. These difficulties are not unique to research in behavioural genetics. However, it does seem that such research is, at present, particularly susceptible to reporting which, whether strictly accurate or not, is misleading in the impression it gives to the reader (Nuffield Council on Bioethics,' 11.13).

As a simple and striking illustration of this worry I want us to briefly look at how the Nuffield report was presented in The Times. The Nuffield chapter on legal responsibility concludes that "genetic variants in the normal range are unlikely to be considered an excuse for legal purposes, at least for the foreseeable future", adding that "they fall outside the scope of the defences of insanity and diminished responsibility and cannot be said to absolve individuals from responsibility for their actions" (Nuffield Council on Bioethics, ${ }^{1}$ 14.24).
The Times headline for its review of the Nuffield report was: Criminal gene "should mean lighter sentence". ${ }^{3}$ Tor Lezemore, of the Nuffield Council on Bioethics, relates how the council was well aware that the press might misreport their findings. ${ }^{4 *}$

She notes how the press release for the report focused on two issues known to be of particular interest to the media: prenatal selection on the basis of predicted behavioural traits, and legal responsibility. Lezemore notes that, in addition to The Times, several other newspapers plumped for misrepresentative headlines, many deploying the expression "criminal gene".

The Times report is not unique, but it will help if we consider it in a little more detail. At first sight, the journalist's report seems to be considerably more cautious than the headline. The journalist writes that "judges should consider reducing the sentences of convicted offenders if scientists prove that their crimes were influenced by their genes, Britain's most respected biological [sic] ethics group said yesterday". Even here, however, as Lezemore notes, the journalist has transformed the mild "could" of the press release (which states that genetic information could be taken into account) into the much stronger normative "should" in the claim that judges should take such information into account.

The rash headline and the misreporting suggest bad journalism. Rather than focusing on why science reporting is inaccurate, however, I want to follow a clue in the misleading Times article, one that points us toward factors, other than simple error and misunderstanding of science, that seem to be involved in the misleading presentation of behavioural genetics.

[The Nuffield Report] has also added to the controversy over the relative influence of nature and nurture on human behaviour, which was recently stirred by the publication of two books, both serialised in The Times, putting either side of the argument. Oliver James, a psychologist who believes that environmental factors outweigh genes, and Steven Pinker, a neuroscientist who holds that genes are more important, argued the merits of their positions.

This comment is particularly instructive for it points us toward a general reason why behavioural genetics gets to * Thanks to an anonymous JME referee for
pointing me toward this. 
be presented in such diverse ways. The quotation just above relates the Nuffield report to the nature/nurture debate and also lets us know that The Times has seen fit to serialise two popular works pertaining to that debate. ${ }^{56}$ The Times, so far as I can tell (thanks to the LexisNexis online database), has not recently serialised accounts of the disputed findings, unreplicated experiments, and statistical correlations, that constitute "real" behavioural genetics. Why is this? One reason is that people like to read and buy books and magazines that tell them something definite about their origins, nature, and, perhaps, their future. Popular science works on the nature/ nurture debate seem to play this role. This does not imply that newspaper editors are all, in some way or other, committed genetic determinists. The point here is that in light of our interests as non-specialist readers (and purchasers of newspapers and books), there is a pragmatic interest for publishers to present definite explanatory and predictive claims that seem to pertain to each of us individuals. Pinker (pronature) and James (pronurture) both do this; they both offer readers a framework that contextualises and constrains the kinds of narratives we construct to make sense of our lives. Behavioural genetics can thus play the same kind of personal narrative shaping role as that played by, among other things, psychoanalysis, astrology, and Marxism. All of these provide part of an answer to the question: "Why am I the way that I am?". I am the way that I am because of: my genes/my family/natural selection/ the Oedipus complex/my friends/class and socioeconomic structures/culture/ gender/the stars.

The presentation of behavioural genetics is, at least in part, apt to be shaped by our interests in generating narrative explanations of how we, as individuals, get to be the way that we are. This is not to say that the substantive content of research is shaped by such interests, the stress here is upon the way that behavioural genetics is presented. Another example may help: the book jacket of Hamer and Copeland's Living With Our Genes: Why They Matter More Than You Think tells us that: "World-renowned molecular geneticist Dean Hamer has been carrying out cutting-edge research which proves beyond a doubt that we are mostly programmed at birth to behave in the way that we $\mathrm{do}^{\prime \prime}{ }^{7}$ After a speculative opening chapter entitled "The genetic roots of personality" the actual content of the book is much more reserved, and much closer to the cautious tone of the Nuffield report. Consider how odd it would be to run this kind of "bait and switch" in the other direction-that is, the book jacket reads: "Well renowned geneticist points out some interesting genotype/phenotype correlations together with some worries about what they show" while the content of the book establishes the existence of, say, a "gay gene".

Our interest in formulating individual narratives is not the only one that shapes the presentation of behavioural genetics. Behavioural genetics is one key element of the nature/nurture debate and that debate has a substantial political dimension. Recent books, such as the Pinker volume serialised in The Times, have sought to use findings in behavioural genetics to provide support for the idea that our biological and genetic inheritance somehow determines our behavioural (and thus our social) character. ${ }^{68}$ This has, in the view of these writers, implications for our political and moral life. Opponents of this view argue that the very idea of genetic determinism is itself an ideological one.' Biological and genetic determinism are, they argue, reflections of certain economic and social attitudes and these deterministic notions are put to use, illegitimately, in support of the idea that certain social inequalities are somehow "natural" or "inevitable".

The point here is not that one or other point of view in the nature/nurture dispute involves a misrepresentation of behavioural genetics. The point is, rather, that the political dimension of the nature/nurture debate shapes the selection and presentation of findings in behavioural genetics. One key element in the nature/nurture debate, for example, concerns the existence of human cognitive and behavioural universals. Virtually all human beings are capable of learning a natural language. Virtually all human beings exhibit a "startle" reflex. Virtually all human beings exhibit a cluster of emotional responses to other human beings, especially to their offspring or family members and so on. There may be variability in human intelligence but, by and large, virtually all human beings are disposed to be more cognitively able than the cleverest monkey. The argument then runs that it is our genetic inheritance that secures this interspecies difference (while acknowledging that environmental conditions play an essential role in enabling human development). The Nuffield report, by way of contrast focuses exclusively on variable behavioural traits and, in the case of quantitative genetics, focuses upon explanations of the variation within human populations rather than upon human universals. A sociobiologically minded writer puts a selection of findings in behavioural genetics to a particular use and, as such, is not simply reporting the state of current research.

\section{ETHICAL DELIBERATION: THE IMPORTANCE OF GOOD INFORMATION}

This brief review of the Nuffield report will serve, I hope, as a useful reminder of the fact that there are various interests and demands that shape the presentation of behavioural genetic research. Behavioural genetic findings can be put to use as part of broad political projects. Such findings can also be woven into the kinds of narrative construction that we human beings seem to find so compelling. Those who aim to sell newspapers and books recognise the fact that we have these interests in the political and historical aspects of our lives. There is thus considerable pragmatic pressure upon them, competing in a fierce market, to present behavioural genetics in a particular light. If we add to these interests a general lack of understanding of the subtleties of the methodology of behavioural genetics we have an enduring potential for a misrepresentation of this important field of research. in a recent article in The Observer Magazine, for example, Oliver James, a vocal participant in the nature/nurtured debate, dismisses the finding that "propensity to divorce" has a heritability of $0.5 .^{10}$ James's "argument" is that there has been a massive increase in divorce over the past 100 years and "such a massive change could not possibly be caused by genes because it takes millennia, not centuries for new genes to become widespread". Presumably James must reject the robust data that shows that height is heritable, given the increase in our height in the past couple of centuries. James does not seem to understand that heritability is a measure of the variation within a population assuming a fixed environment. Highly heritable traits such as height and, perhaps, intelligence, can be varied for the whole population by changes in the environment. Changes in divorce rates might be entirely down to environmental factors-for example, changes in the law, women becoming financially independent from men etc, even while the propensity to divorce relative to a fixed environment is highly heritable.

The Nuffield report, in contrast to the (occasionally erroneous) ideological and narrative presentation of behavioural genetics found in the media and in popular science, is not something that has been produced in the hope that it will sell truckloads of copies. Nor are the authors of the report offering material that can be used in making sense of our 
individual lives. Finally, although it might be the case that all writing is ideological in some limited sense, the Nuffield report is not seeking to further an ideological position within the politically charged nature/nurture debate. Its aim, rather, is to give us a review of the complex and limited nature of contemporary behavioural genetics (at least with regard to behavioural traits in the normal range).

For those of us who do not practise first order research in behavioural genetics our knowledge of behavioural genetics is acquired "second hand" via the testimony and texts of others. Many of us wonder and worry about the practical applications and ethical implications of developments in this field, but decent ethical deliberation requires accurate information. Unlike many presentations of behavioural genetics in the media and in the popular science press, the Nuffield report gives a nonpartisan, non-profit making survey of one broad and significant area of behavioural genetics and, as such, it provides an extremely valuable resource for those concerned with the ethical implications of developments in behavioural genetics.

J Med Ethics 2004;30:601-604.

doi: 10.1136/jme.2003.002196

Correspondence to: Dr N C Manson, King's College, Cambridge, CB2 1ST, UK;

neil.manson@kings.cam.ac.uk

Accepted for publication 13 June 2003

\section{REFERENCES}

1 Nuffield Council on Bioethics. Genetics and human behaviour: the ethical context. London:
Nuffield Council on Bioethics, $2002 \mathrm{http} / / /$ www.nuffieldbioethics.org/publications/ pp_0000000015.asp (accessed

21 July 2004).

2 Tang Y, Shimizu E, Dube G, et al. Genetic enhancement of learning and memory in mice. Nature 1999;401:63-9.

3 Henderson M. Criminal genes "should mean lighter sentences". The Times, 2002 Oct 2, 5.

4 Lezemore T. Genes, behavior, and the media. Hastings Cent Rep 2002;32:6-7.

5 James $O$. They $f^{* * *}$ you up: how to survive family life. London: Bloomsbury, 2002.

6 Pinker S. The blank slate: the modern denial of human nature. London: Penguin, 2002.

7 Hamer D, Copeland P. Living with our genes: why they matter more than you think. London: Macmillan, 1999.

8 Fukuyama F. Our posthuman future: consequences of the biotechnology revolution. London: Profile, 2002.

9 Rose S, Lewontin RC, Kamin L. Not in our genes: biology, ideology and human nature. London: Pantheon, 1984

10 James O. Make or break: divorce rates have risen from five a year to 165000 , but it's not all bad. The Observer Magazine 2003 Mar 2:71. 